\title{
LA PERCEPCIÓN DE LA NOTA ROJA PERIODÍSTICA EN PRIMERA PLANA. UN ESTUDIO DE CASO
}

Laura Flores-Gómez: Benemérita Universidad Autónoma de Puebla. México lahora fg@hotmail.com

Angélica Mendieta-Ramírez ${ }^{\mathbf{1}}$ : Benemérita Universidad Autónoma de Puebla. México angelicamendietaramirez@yahoo.com.mx

\section{RESUMEN}

La presente investigación tiene como objetivo analizar la percepción de los transeúntes de la ciudad de Puebla al ver o leer la primera plana de un diario enfocado a la nota roja, esperando que los aportes manejados en las siguientes líneas orienten a la reflexión y la concientización sobre las distintas alternativas para ser informado e impulse una nueva visión sobre un ambiente con menor violencia. En este sentido la propuesta se dirige hacia los ciudadanos que atestiguan la experiencia de elección frente a comercios de medios de comunicación escritos, específicamente, puestos de periódicos; ofreciéndoles alternativas de lectura que amplíen su panorama y visión ante los acontecimientos cotidianos relacionados con delincuencia, muerte y sufrimiento. Bajo este contexto, se plantean las siguientes interrogantes: a) ¿Qué percepción tienen las personas a evaluar a cerca de la nota roja escrita en primera plana, difundida en la ciudad de Puebla?; b) ¿Cuál es la estructura y los elementos de la nota roja? y c) ¿Cuál es la función de la nota roja?.

PALABRAS CLAVE: Comunicación - Nota Roja - Percepción - Periodismo - Periódico 'Metro'

\section{THE JOURNALISTIC CRIME TABLOID PERCEPTION ON THE FRONT PAGE. A CASE STUDY}

\footnotetext{
${ }^{1}$ Autor correspondiente

Angélica Mendieta Ramírez: Profesora-Investigadora de Tiempo Completo de la Facultad de Ciencias de la Comunicación de la Benemérita Universidad Autónoma de Puebla. México Correo: angelicamendietaramirez@yahoo.com.mx
} 


\section{ABSTRACT}

This research aims to analyze the perception of passersby in the city of Puebla to see or read the front page of a newspaper focused on the sensationalist, hoping that the contributions handled in the following lines to guide reflection and awareness the alternatives to be informed and promote a new vision of an environment with less violence. In this regard, the proposal is directed towards the citizens who attest to the experience of choice in shops in print media, specifically, newsstands, offering alternatives to broaden their outlook reading and vision to everyday events related to crime, death and suffering. In this context, raises the following questions: a) What are the perceptions people evaluate about the red note written on the front page spread in the city of Puebla? b) What is the structure and elements of the sensationalist? and c) What is the function of the red note?.

KEY WORDS: Communication - Red Note - Perception - Journalism - Newspaper 'Metro'

\section{INTRODUCCIÓN}

En la comunicación se engloban los medios de difusión y su interacción con la sociedad, la expresión, los gestos y la información e interpretación de la misma. La influencia que ejercen la televisión, la radio, Internet y el periódico sobre una persona, posibilita que ésta adopte un criterio en relación con el contenido que le es proporcionado. En esta investigación, se aborda el tema de la nota roja periodística, específicamente sobre los efectos que ejerce en el lector el contacto visual o la lectura del diario Metro distribuido en la ciudad de Puebla y especializado en la difusión de nota roja.

La nota roja es un género periodístico muy relevante por su enorme difusión e influencia sobre los lectores, la cual requiere ser cuidadosamente analizada para que en la práctica, el consumo de la sociedad tenga alternativas de información y conocimiento al margen de la proporcionada por un medio sensacionalista como Metro. Sobre esta línea recae el término reflexivo entorno a la comunicación educativa que pretende: "...compartir, abrir caminos a la reflexión, apoyar la recuperación de la experiencia, relacionar texto y contexto, jugar y gozar la expresión, respetar al otro y permitir la riqueza de la comunicación cotidiana. Su implementación facilita al individuo la comprensión de diferentes procesos, acompaña el aprendizaje y ofrece recursos para leer su contexto social y realidad' (Prieto, 1998 citado en Moreno, 2002).

Dicha comunicación, da sustento a la propuesta presentada en este documento al proponer redireccionar la mirada a otros periódicos al momento de ejecutar la lectura. Los medios deben presentar la información de tal modo que sus ejemplares motiven a la reflexión; para esto deben ser sobrios y permitir que sus líneas sean legibles e inteligibles para sus seguidores, es decir, el medio debe persuadir al lector de adquirirlo todos los días con la calidad de sus contenidos, esto es, con la noticia 
Comunicación - Nota Roja - Percepción - Periodismo - Periódico 'Metro'

pertinente redactada sobria y clara. No obstante, estas características no son primordiales en un periódico sensacionalista, al cual "nunca se le podrá exigir el empleo de un vocabulario distinto al que lo caracteriza; sin embargo, se puede invitar al tratamiento veraz de la información que es difundida" (López, 1995). En este sentido el sensacionalismo y la veracidad no necesariamente deben confrontarse, pues como medios de información es indispensable regirse por una ética profesional y una responsabilidad por presentar la información real, evitando dañar a terceros (Jáquez, 2010).

La hipótesis que guió el presente trabajo es: "la nota roja es un género periodístico con la presentación de imágenes y encabezados poco cuidados en primera plana, generando percepciones negativas en los transeúntes al tener un contacto visual o de lectura con ellas".

\section{METODOLOGÍA}

En la metodología del estudio, se describen las personas evaluadas en la investigación; La percepción de la nota roja periodística en primera plana en la ciudad de Puebla: 2010.

El trayecto de esta investigación parte de una visión cualitativa, sin embargo su orientación fue propiciando la aplicación de una investigación mixta, la cual "implica combinar los enfoques cuantitativos y cualitativos en un mismo estudio" (Hernández, 2006). Los instrumentos utilizados fueron: análisis de contenido de la primera plana del periódico Metro realizado durante una semana, y encuesta aplicada a distintas personas, delimitada bajo el rango de alcance e interés.

Desde el punto de vista cualitativo, el análisis de contenido es arrojado de manera sintetizada en esta investigación. No obstante, el interés recae en la muestra representativa, su característica cuantitativo; en primer lugar se tomaron en cuenta particularidades específicas: mujeres y hombre mayores de 18 años y transeúntes de las principales plazas distribuidas en cuatro puntos de la ciudad de Puebla, que contaran con un puesto de periódicos a la vista, ya que esto permitiría el reconocimiento inmediato de escritos de nota roja, mostrando su impresión por dicho género. Este sector al no estar contabilizado como transeúnte por el Instituto Nacional de Estadística y Geografía (INEGI), se consideró a los habitantes de las colonias próximas o cercanas a las plazas designadas y se tomaron en cuenta de manera equitativa cinco colonias por zona:

- Plaza dorada: Colonia Huexotitla, San Baltazar Campeche, Fraccionamiento Anzures, Ladrillera de Benitez y Colonia el Carmen.

- Plaza Cruz del Sur: Colonia Viveros, Santa Cruz Buena Vista, Colonia Independencia, Unidad Habitacional Hermenegildo Galeana y Villa Olímpica.

- Centro comercial Angelópolis: Club de Golf, Mayorazgo, Rivera de Atoyac, Habitacional la Noria, San Miguel de la Rosa.

- Zona CAPU: Ampliación San Felipe, Fraccionamiento San Bernardo, Jorge Murad, Cleotilde Torres, Sta. María la Rivera.

Tabla 1. Zonas designadas para la aplicación de encuestas 


\begin{tabular}{|l|l|}
\hline $\begin{array}{l}\text { Plaza designadas dados los } 4 \\
\text { puntos cardinales }\end{array}$ & $\begin{array}{l}\text { Población total mayores de 18 } \\
\text { años y más entre hombres y } \\
\text { mujeres }\end{array}$ \\
\hline - Cruz del sur & $\bullet 3413$ \\
\hline - Pza. Dorada & $\bullet 13745$ \\
\hline - Angelópolis & $\bullet 2551$ \\
\hline - CAPU & $\bullet 4349$ \\
\hline - Resultado final de la suma de & $\bullet 24,058$ \\
\hline
\end{tabular}

Fuente: Elaboración propia diseñada para esta investigación: 2010, con resultado del conteo habitacional INEGI 2006

Finalmente, y tras el proceso de selección, se presenta la siguiente fórmula propuesta por Marcela Benassini (2009), que describe el significado de cada variable.

Tabla 2. Metodología y aplicación

\begin{tabular}{|c|c|}
\hline Tipo de Investigación & Explicativa \\
\hline Enfoque & Mixto \\
\hline Instrumento de medición & $\begin{array}{l}\text { Análisis de contenido. } \\
\text { Encuesta de } 10 \text { preguntas. }\end{array}$ \\
\hline Muestra $\longrightarrow$ & $\begin{array}{l}\text { Esta representación designa un universo } \\
\text { de } 24,050 \text { personas. Al emplear la } \\
\text { fórmula las reduce a } 378 \text { a encuestar. }\end{array}$ \\
\hline Selección $\longrightarrow$ & $\begin{array}{l}\text { Para facilitar la aplicación dadas las } \\
\text { limitantes económicas y temporales, se } \\
\text { dividieron en cuatro partes iguales. }\end{array}$ \\
\hline $\begin{array}{l}\text { Para un } 95 \% \text { de confianza, se tiene } \\
\text { que: } \\
\mathrm{P}=\text { Probabilidad de que se realice el } \\
\text { evento } \\
q=\text { Probabilidad de que no se } \\
\text { realice el evento } \\
\mathrm{E}=\text { Error permitido, el cual es de un } \\
5 \% \\
\mathrm{~N}=\text { Tamaño de la población }\end{array}$ & Aplicado el mes de Octubre de 2010 \\
\hline
\end{tabular}

\section{ANÁLISIS Y DISCUSIÓN}

\subsection{Antecedentes de la nota roja}

La indiscutible trascendencia de la nota roja tiene muchas lecturas. El género va más allá de la simple exposición de noticias o hechos relacionados con la violencia, la sangre y la delincuencia, según el cronista mexicano, la nota roja convierte "/os 
Comunicación - Nota Roja - Percepción - Periodismo - Periódico 'Metro'

crímenes más notorios en expresión artística y ve en los hechos de sangre los cuentos de hadas de las mayorías"(Monsiváis, 2010).

Las percepciones y los análisis que investigadores y catedráticos hacen de la nota roja son variados. Este género nació en 1526, cuando un grupo de hombres, bajo el influjo del alcohol, atentó contra la Preeminencia de la Santa Inquisición y como respuesta al ataque, las autoridades eclesiásticas ejecutaron a cuarenta y tres personas y cientos fueron castigados. Tras las sanciones, en las puertas de las iglesias se colocaron edictos con un sello rojo que anunciaba a la sociedad la ofensa cometida, símbolo que dio origen a lo que hoy conocemos cono nota roja (Álvarez, 2002). "La nota roja está definida por su interés en los actos 'desviados': robos, asesinatos, tragedias, encarcelamientos, ejecuciones. En el proceso de describir-narrar un suceso, la nota define y da forma no sólo a ese suceso, sino a las grandes articulaciones presentadas en un escenario más amplio, el de la praxis social"(Arriaga, 2002).

Entre las distintas tendencias del periodismo, surgió el amarillismo, escrito para el ciudadano común, es decir, para las clases bajas. La despreocupación por la ética y el bien informar generó desagrado y desconfianza en el lector, la cual llegó hasta la iglesia, y los periódicos tuvieron que retomar la línea discursiva delimitada a la realidad de los hechos. Sin embargo, el sensacionalismo se convirtió en una herramienta necesaria para que un periódico se diera a conocer, (De Fleur, y BallRokeach, 1999) al utilizar la presentación de noticias destacando sus aspectos más llamativos para producir una fuerte impresión (García-Pelayo, 1988).

The New York World fue el primer periódico del mundo en divulgar las tiras amarillas, donde apareció el famoso personaje creado por R. F. Outcault, Yellow Kid, que en 1896 alcanzó una gran popularidad en el diario y entre la alta sociedad motivada por dicha caricatura, lo que otorgó al periodismo sensacionalista el título de "la prensa amarilla" (Lara y Barata, 2009), este tipo de periodismo: "Se apropió de las técnicas de redacción, ilustración e impresión que eran el orgullo de la nueva prensa, y las subvirtió. Transformó el drama de la vida en un melodrama barato y falseó los hechos cotidianos para darles la forma que consideró más apta para aumentar las ventas. Y lo que es peor, en vez de servir de guía a los lectores, les ofreció un paliativo de pecado, sexo y violencia"(De Fleur y Ball-rokeach, 1982; citado en Lara y Barata, 2009).

En 1997 se llevó a cabo una investigación de análisis comparativo en los periódicos impresos 'Excélsior', de la ciudad de México, y 'El Tiempo', de Bogotá, Colombia, con respecto a su contenido de nota roja. Con ello se mostró la similitud de contenidos, donde los puntos analizados fueron las funciones, las acciones y la narración (Arriaga, 2002). Este trabajo permitió ampliar el estudio del concepto de la nota roja a partir de los desastres en los que vivió y vive Latinoamérica. Algunos periódicos, bajo gestos o expresiones textuales, inevitablemente colocaron al morbo en lugar de las actitudes morales como prioridad (Monsiváis, 2010).

Distintos estudiosos sitúan el nacimiento de la nota roja en México "tras la llegada de los españoles, pues se instalaron los llamados cabildos, los cuales tenían como misión difundir las noticias que el consejo creaba o generaba de lo que ahora es la ciudad de México" (Álvarez, 2002). Sin embargo Octavio Paz ve el transcurso histórico de la nota de un modo más poético: "Los Cristos ensangrentados de las iglesias pueblerinas, el 
humor macabro de ciertos encabezados de los diarios, 'los velorios', la costumbre de comer el 2 de noviembre panes y dulces que fingen huesos y calaveras, son hábitos, heredados de los indios y españoles, inseparables de nuestro ser. Nuestro culto a la muerte es culto a la vida, en anhelo de muerte. El gusto por la autodestrucción no se deriva nada más de tendencias masoquistas, sino también de una cierta religiosidad" (Paz, 1959)

Se ha señalado que no se puede separar la nota roja de los periódicos, pero expone que se podría mostrar de manera distinta, de tal suerte que el lenguaje y su escritura se mejoren, intentando evitar las presentaciones alarmistas, e incluso sugiere que los medios se respalden en un código de ética ante una sociedad que se ha vuelto más exigente, analítica y crítica (Jáquez, 2010). Paralelo a este acontecimiento, la prensa mexicana atravesó un momento complicado al carecer de financiamiento, y se obligó a describir hechos y enfoques que favorecieran el consumo de este medio, encaminando sus esfuerzos a que las personas voltearan y vieran encabezados atractivos que pudieran estimularlos a la compra. Los reporteros optaron por dar su opinión de la noticia, creando rumores y logrando que las riñas callejeras se convirtieran en los nuevos contenidos atrayentes. En gran medida, el empleo de este tipo de nota fue llegando por los dilemas y enfrentamientos políticos (Irving, 2000).

El acercamiento de la gente a periódicos de nota roja es común, y la existencia de medios con otro enfoque no ha cambiado el uso y consumo de sus notas. Vale la pena entonces citar que en Puebla se identifica por su circulación, por su tiraje y por su distribución medios escritos enfocados a este tipo de publicaciones (Tirado, 2004):

'El Sol de Puebla', supo colocarse en el gusto e interés del público, comenzó a circular el 5 de mayo de 1944. Su creador José García Valseca, diseñaba un periódico que generaba descontento en muchas personas, sobre todo por parte de la iglesia y el ámbito universitario, pero antes de mantener esa imagen, implementó el equipo ofset que dio paso a las publicaciones de color; de esta forma, concilió con quienes en un principio no coincidían con él y se distribuyó sin contratiempos (Tirado, 2004).

'Intolerancia' surge como una revista de nuevas propuestas. Con el paso del tiempo, se posicionó como un medio cuyo formato de contenidos fue orientado al sensacionalismo, permitiendo el uso de los comentarios personales en sus páginas (Tirado, 2004). Ante este modo de escribir, el periodista Mario Alberto Mejía, fundador del portal La Quinta Columna en Puebla, señala que "no se concibe el periodismo sin un toque de sensacionalismo, de lo cual hay constancia en la prensa mundial y, sobre todo, la nacional' (Tirado, 2004). Es así como la nota roja engloba la crónica de sucesos criminales (Lara y Barata, 2009).

En el periódico 'Metro', Cristian Ampudia, editor de deportes y quien lleva dos años colaborando para este medio no sólo en la sección deportiva, sino también en el diseño de las primeras planas del periódico, proporcionó información histórica del medio, señala que "tuvo sus comienzos en Monterrey, para luego expandirse a Guadalajara y más tarde a México, ciudad en la que van doce años de su existencia. Poco más tarde, Toluca y Puebla abrieron sus puertas al medio, lugares en los que ha 
Comunicación - Nota Roja - Percepción - Periodismo - Periódico 'Metro'

logrado un tiraje de 15 mil ejemplares. En el estado de México de su tiraje asciende a los 80 mil, y en ocasiones tiene mayor éxito. El número de impresiones ha dependido del impacto, gracia o empatía con que los encabezados han atraído más compras, teniendo ciertas portadas que fueron reimpresas" (Ampudia, 2011).

\subsection{Perspectivas de la nota roja}

La información es parte de la estructura y de los objetivos que el periódico Metro busca difundir entre su público meta, y para poder sustentar todo el proceso de investigación se hace preciso acudir al respaldo teórico. La teoría del significado engloba características de la percepción, a partir del momento en que una nota se da a conocer, el individuo puede alterar la traducción de la realidad; por citar un ejemplo, la prensa escrita del siglo XIX difundía imágenes distorsionadas o falsas sobre lo que acontecía en el mundo (De Fleur y Ball-Rokeach, 1996), generando interpretaciones diversas en el lector. Este problema social ha provocado controversia al presentar los hechos que describen la violencia. Las malas noticias, a pesar de ser malas, resultan necesarias para el conocimiento de las personas, y son más requeridas en el caso de las notas sensacionalistas, las que de acuerdo a la teoría son identificadas como explosiones, porque detallan información detonante, como los crímenes y todas las desgracias humanas. Éstas han demostrado una mayor mención en las conversaciones de las personas que destacan al género, y ponen en alerta a la sociedad (Gomis, 1997).

Sobre un mismo eje, la teoría funcionalista se respalda en la relación que existe entre los medios de comunicación y la sociedad. Para su comprensión, son esenciales algunos factores; la integración, la cooperación, el orden, el control y la estabilidad, la adaptación a los cambios, la movilización y la continuidad de la cultura y de los valores (McQuail, 1997). Cabe mencionar que el funcionalismo tiene que ver con las instituciones formales e informales. De esta manera se analiza a la familia, la escuela y los medios de comunicación (Reyes, 1999). No se centra en un conflicto del hombre, sino "el conflicto se centra en los medios que afectan a los hombres, por lo cual la sociedad puede guardar cierto equilibrio, mientras los medios se transforman y nos transforman" (Paoli, 2005).

El funcionalismo desea encontrar indicios del porqué del comportamiento humano (Paoli, 2005), y sugiere que las noticias y la información que se presenta en los medios, se fundamente en normativas que alientan la vinculación entre ellos y las masas, en los que puedan hallar cierta seguridad (McQuail, 1997).

Con este análisis se fueron formando líneas y parámetros para la aplicación de métodos específicos en este documento. Las aportaciones de las tres teorías que lo sustentan, detallan el impacto en la sociedad.

En el caso de las organizaciones -mercantiles especialmente- la sensibilidad a los impactos informativos negativos es muy alta: "La actitud de los medios de comunicación ante un acontecimiento negativo en una empresa, va más rápido que lo que tarda la propia empresa en reaccionar ante el mismo. Los medios acaparan la información del suceso y crean un estado de opinión que obliga a la empresa a justificarse sobre los acontecimientos sufridos" (Caldevilla, 2009). 


\subsection{Periódico 'Metro'}

Gráfica 1. Periódicos de nota roja

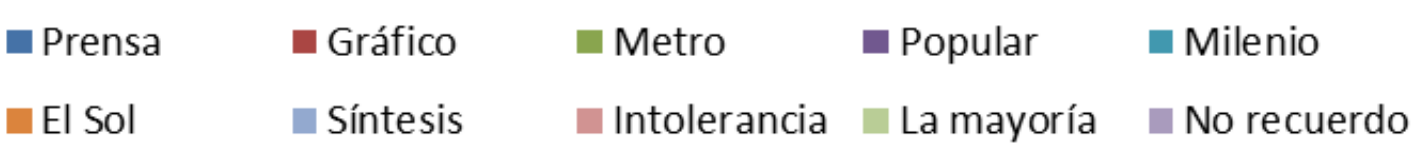

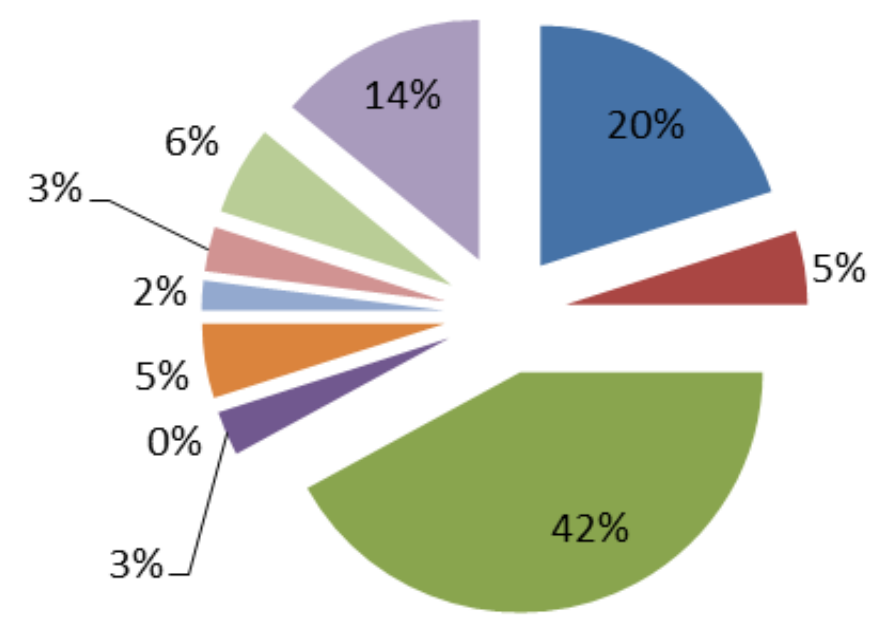

Fuente: Elaboración propia con los resultados obtenidos de encuestas especialmente diseñadas para esta investigación: 2010

Lo más interesante de esta gráfica radica en el concepto que las personas tienen de nota roja, basado en ello respondieron a la pregunta, de tal modo que el $42 \%$ de las personas identifican al periódico Metro entre los medios escritos con mayor utilización del recurso amarillista, el $20 \%$ lo asocia a la Prensa, un $14 \%$ que no recordaban en específico un medio empleador del género en sus portadas, disminuyendo el porcentaje, aparece la respuesta "la mayoría" de la que el $6 \%$ calificó a los medios, valiéndose del recurso de nota roja, el $5 \%$ asoció el término al periódico El Sol de Puebla, mientras que el 3\% lo encuentra en Intolerancia a la par que en el Popular, finalmente el $2 \%$ mencionó a Milenio entre los medios escritos de este corte. Destacando una gran diferencia de porcentajes entre Metro y Milenio, considerados por las personas como medios de nota roja.

Gráfica 2. Percepción de nota roja en portada 


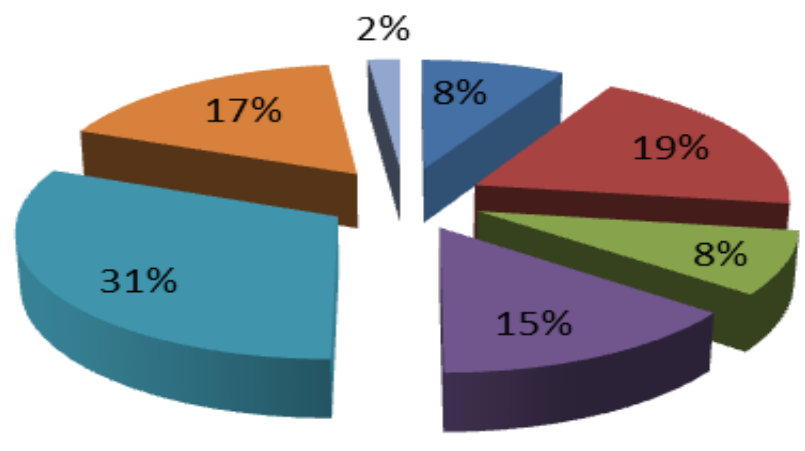

Es ofensa para los afectados

- Se aprovechan de las desgracias para vender

- La realidad de nuestra sociedad

- Otra manera de informar

- Incita el morbo

- Genera más violencia

Fuente: Elaboración propia con los resultados obtenidos de encuestas especialmente diseñadas para esta investigación: 2010

De las trescientos treinta y ocho encuestados, el $31 \%$ coinciden en que incita al morbo, el $19 \%$ consideran que se aprovechan de las desgracias, el $17 \%$ sienten que genera más violencia, mientras que el $15 \%$ señalaron que es otra manera de informar. Existe un empate entre las opciones: mostrar la realidad de nuestra sociedad y ser una ofensa para los afectados, con un $8 \%$ que lo sugirieron, mientras que, tan solo el $2 \%$ opinan que estas notas previenen la violencia.

Gráfica 3. Sensaciones que provoca la nota roja

-Desagrado $\square$ Tristeza Enojo $\square$ Nada Inseguridad

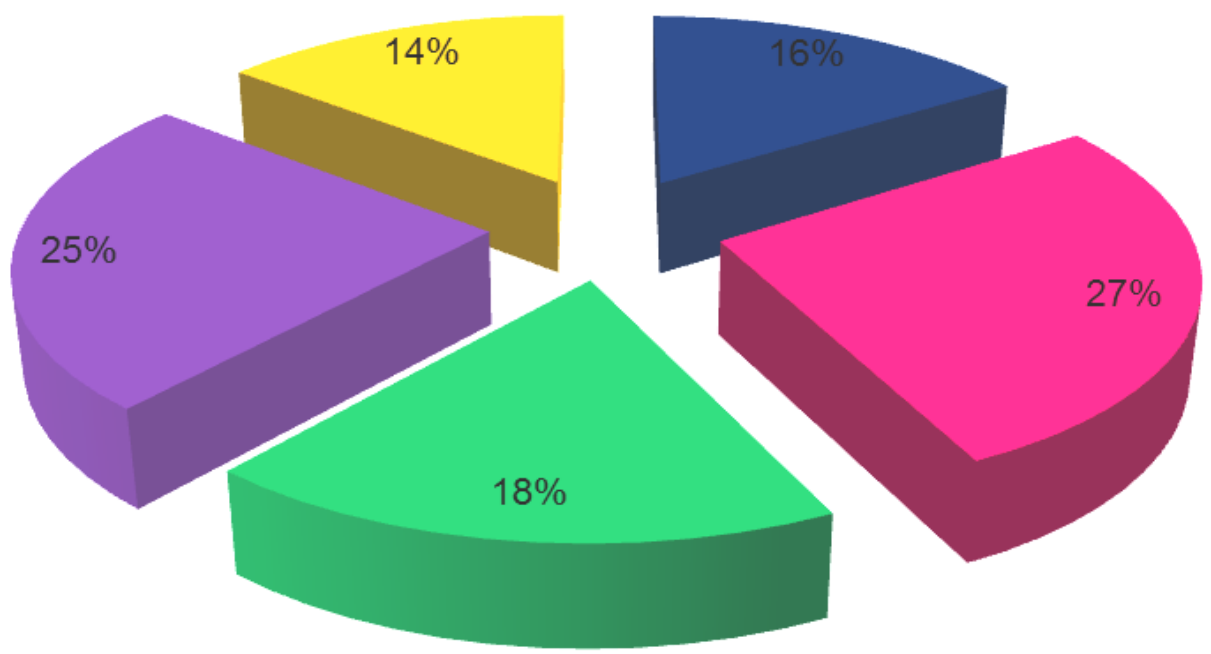

Fuente: Elaboración propia con los resultados obtenidos de encuestas especialmente diseñadas para esta investigación: 2010 
El sentimiento predominante es la tristeza al ver tanta violencia, sangre o personas lastimadas que destacó con un $27 \%$, el $18 \%$ manifestó sentir enojo, emoción en la que se englobó la impotencia al percatarse de ello; el $16 \%$ dijo sentir desagrado, incluyendo en este sentir al asco; el último porcentaje con un $14 \%$ mencionó inseguridad, resaltando en este último, que el país va en decadencia.

Finalmente cabe destacar que de las diez preguntas realizadas al público objetivo, tres fueron revaloradas para la interpretación de esta investigación, ya que cuentan con parte de las características presentadas en la propuesta.

Tabla 3. Abstracto del análisis de contenido

\begin{tabular}{|c|c|c|c|c|c|c|}
\hline $\begin{array}{l}\text { Portadas } \\
\text { Metro }\end{array}$ & $\begin{array}{l}\text { Fecha y } \\
\text { ubicación }\end{array}$ & Encabezado & $\begin{array}{l}\text { Fotografía- } \\
\text { imágenes }\end{array}$ & $\begin{array}{l}\text { Tipo de } \\
\text { noticia }\end{array}$ & $\begin{array}{l}\text { Palabras } \\
\text { recurrentes }\end{array}$ & Complementos \\
\hline $\begin{array}{l}\text { Unidad } 1 \\
\text { Día Lunes }\end{array}$ & $\begin{array}{l}\text { 20/septiem } \\
\text { bre/ 2010- } \\
\text { Lugar: } \\
\text { Clavijero }\end{array}$ & $\begin{array}{l}\text { "Se proyecta } \\
\text { unos } 25 \text { metros } \\
\text { en el peri } \\
\text { SALE } \\
\text { VOLANDO" }\end{array}$ & $\begin{array}{l}\text { Un hombre } \\
\text { con collarín, } \\
\text { mucha } \\
\text { sangre en el } \\
\text { rostro y } \\
\text { manos. Se } \\
\text { identifica a } \\
\text { un par de } \\
\text { personas de } \\
\text { servicios } \\
\text { médicos, lo } \\
\text { llevan en una } \\
\text { camilla. }\end{array}$ & $\begin{array}{l}\text { Accidente } \\
\text { (Enviado a } \\
\text { nota de } \\
\text { Seguridad) }\end{array}$ & $\begin{array}{l}\text { Sale } \\
\text { volando }\end{array}$ & $\begin{array}{l}\text { Menciona la } \\
\text { nota de las } \\
\text { próximas } \\
\text { páginas, } \\
\text { destacadas por } \\
\text { palabras e } \\
\text { imágenes que } \\
\text { llaman la } \\
\text { atención. }\end{array}$ \\
\hline $\begin{array}{l}\text { Unidad } 2 \\
\text { Día } \\
\text { Martes }\end{array}$ & $\begin{array}{l}\text { 21/septiem } \\
\text { bre/2010- } \\
\text { Lugar: } \\
\text { Jalpan }\end{array}$ & $\begin{array}{l}\text { "Derriba lluvia } \\
\text { puente de la vía } \\
\text { México Tuxpan } \\
\text { DEVASTADOR" }\end{array}$ & \begin{tabular}{|l} 
El camino del \\
puente \\
destruido, \\
con algunas \\
personas que \\
a lo lejos \\
observan el \\
incidente.
\end{tabular} & $\begin{array}{l}\text { Desastres } \\
\text { naturales. } \\
\text { (Enviado a } \\
\text { nota local) }\end{array}$ & Devastador & $\begin{array}{lr}\text { Menciona } & \text { la } \\
\text { nota de } & \text { las } \\
\text { próximas } & \\
\text { páginas, } & \\
\text { destacadas } & \text { por } \\
\text { palabras } & \text { e } \\
\text { imágenes } & \text { que } \\
\text { llaman } & \text { la } \\
\text { atención } & \end{array}$ \\
\hline
\end{tabular}

Fuente: Elaboración propia, diseñada para esta investigación: 2010

\section{CONCLUSIONES}

Esta investigación busca ser una propuesta de desarrollo para los lectores, con quienes siempre se está en deuda. La problemática actual está vinculada a: la educación y visión de las nuevas generaciones, la ética periodística, la desinformación, el lenguaje, las imágenes y el daño a terceros. 
Comunicación - Nota Roja - Percepción - Periodismo - Periódico 'Metro'

Durante el análisis de resultados se comprobó la hipótesis: la nota roja es un género periodístico cuyas imágenes y encabezados poco cuidados en primera plana generan percepciones negativas en los transeúntes. Ante este contexto surgen propuestas contempladas como alternativa de lectura y consumo, elegidas por su periodicidad, su contenido y su propuesta de difusión de la noticia:

Tabla 4. Propuesta de lectura

\begin{tabular}{|c|c|c|}
\hline $\begin{array}{l}\text { PERIÓDICO } \\
\text { ANALIZADO }\end{array}$ & \multicolumn{2}{|c|}{ PROPUESTAS } \\
\hline $\begin{array}{l}\text { Inicia en Monterrey } \\
\text { hace 12 años y } \\
\text { continúa su labor en } \\
\text { Guadalajara y México. } \\
\text { Después se instala en } \\
\text { Toluca y Puebla. De } \\
\text { estos dos últimos } \\
\text { estados, } \\
\text { ejemplares han sido } \\
\text { vendidos (Ampudia, } \\
2010 \text { ) }\end{array}$ & $\begin{array}{l}\text { LaJOrnada } \\
\text { Periódico que nace en } 1984 . \\
\text {-Socios iniciadores, artistas: } \\
\text { Rufino Tamayo y Francisco } \\
\text { Toledo. } \\
\text { Colaboradores: Monsiváis, } \\
\text { Octavio Paz, Carlos Fuentes, } \\
\text { Umberto Eco, entre otros. } \\
\text {-Constituido por: periodistas, } \\
\text { científicos, académicos, } \\
\text { escritores, artistas, cineastas, } \\
\text { fotógrafos, militantes políticos de } \\
\text { varias tendencias, luchadores } \\
\text { sociales. Se involucraron poetas, } \\
\text { obreros y estudiantes (Lira, 2011) } \\
\text {-Cuando Chiapas se enfrentó a } \\
\text { situaciones militares, las } \\
\text { fotografías de personas fallecidas, } \\
\text { iban acompañadas de una reseña } \\
\text { histórica, un análisis religioso y } \\
\text { cultural, un }\end{array}$ & $\begin{array}{l}\text { ELL UNIVERSAL } \\
\text { Fundado el } 1 \text { de octubre de } 1916 . \\
\text { Enero de } 1921 \text { adopta el lema de "El } \\
\text { Gran Diario de México". } \\
1 \text { de febrero de } 1922 \text { una edición } \\
\text { vespertina: EL UNIVERAL Gráfico. (El } \\
\text { Universal en línea, 2010) } \\
23 \text { de octubre de 1969, Juan Francisco } \\
\text { Ealy Ortiz asume la Presidencia y } \\
\text { Dirección General. } \\
\text { Criterios ante violencia: No explota la } \\
\text { tragedia de terceros con el fin de } \\
\text { generar mayor lectoría o audiencia, por } \\
\text { lo que rechaza la información y los } \\
\text { contenidos de corte sensacionalista, lo } \\
\text { que incluye textos o imágenes expresas } \\
\text { de víctimas de la violencia. }\end{array}$ \\
\hline
\end{tabular}

Fuente: Elaboración propia especialmente diseñadas para esta investigación: 2010

Se plantean tanto su viabilidad como la inviabilidad de la propuesta:

Tabla 5. Propuesta

\begin{tabular}{|l|l|}
\hline \multicolumn{1}{|c|}{ Propuesta } & \multicolumn{1}{c|}{ Viabilidad } \\
\hline $\begin{array}{l}\text { Ser un documento que proporcione } \\
\text { información que dé paso a otros } \\
\text { aportes o estudios. }\end{array}$ & $\begin{array}{l}\text { En el proceso de investigación, siempre } \\
\text { se requieren estudios que propongan } \\
\text { alternativas; este trabajo sería una de } \\
\text { ellas. }\end{array}$ \\
\hline $\begin{array}{l}\text { Sugerir otros medios de difusión } \\
\text { periodística para su lectura. }\end{array}$ & Son periódicos reconocidos. \\
\hline
\end{tabular}

Fuente: Elaboración propia especialmente diseñada para esta investigación: 2010. 
En el cuadro se proponen dos ideas encaminadas a redireccionar el consumo de nota roja, por un lado, esta investigación, busca ser una añadidura de otros aportes y por otro, sugiere medios de comunicación periodística que aborden la información diferente, esto, con la finalidad de abrir el panorama y la mente del individuo, que no se incline solo por un periódico; sino que encuentre oportunidad de seguir las noticias a través de otros.

\section{REFERENCIAS}

Álvarez, M. (2002). La producción de la nota roja en Guadalajara, en Revista Universidad de Guadalajara. Disponible en: www.cge.udg.mx/revistaudg/rug22/rug22dossier1.html (Consultado el 20/07/2010)

Arriaga, J. (2002). 'Colombianización' o 'mexicanización' periodística. La nota roja en los noventa, en Razón y Palabra. Disponible en: www.razonypalabra.org.mx/anteriores/n26/jarriaga.html (Consultado el 20/07/2010)

Caldevilla, D. (2009). Comunicar en situaciones de crisis, en Revista de Comunicación Vivat Academia.

Disponible

en: www.ucm.es/info/vivataca/numeros/n105/innovaci.htm\#david (Consultado el día 30/08/2010)

De Fleur, L., \& Ball Rockeach, S. (1993). Teorías de la comunicación de masas. Barcelona: Paidós.

García-Pelayo, R. (1988). Diccionario enciclopédico ilustrado. Madrid: Larousse.

Gomis, L. (1997). Teoría del periodismo: cómo se forma el presente. Barcelona: Paidós.

Hernández, R., Collado, C. \& Baptista, P. (2006). Metodología de la investigación. México: McGraw-Hill.

Jáquez, J. (2001). La prensa amarillista en México en Revista Latina de Comunicación Social. Disponible en: www.ull.es/publicaciones/latina/2001/latina38feb/123jaquez.htm (Consultado el día $31 / 08 / 2010)$

Lira, C. (2011). La sociedad en el espejo de las princesas, en La jornada. Disponible en: www.jornada.unam.mx/info/ (Consultado 30/11/2011). 
Comunicación - Nota Roja - Percepción - Periodismo - Periódico 'Metro'

López, M. (1995). Como se fabrican las noticias, fuentes, selección y planificación. Barcelona: Paidós.

McQuail, D. (1997). Introducción a la teoría de la comunicación de masas. Barcelona: Paidós Comunicación

Monsiváis, C. (2010). Los mil y un velorios: Crónica de la nota roja en México. México: Debate.

Moreno, L. (2002). Educación, comunicación e imaginarios sociales, en Razón y Palabra. Disponible en: www.razonypalabra.org.mx/anteriores/n25/lmoreno.html (Consultado el 6/11/2011)

Paoli, A. (2005). Comunicación e información, perspectivas teóricas. México: Trillas.

Paz, O. (1959). El laberinto de la soledad. México: FCE.

Reyes, O. (1999). Ensayo crítico sobre paradigmas de la comunicación en Razón y Palabra. Disponible en: www.razonypalabra.org.mx/anteriores/n15/oreyesh15.html (Consultado el 26/03/2011).

Tirado, G. (2004) Voces e imágenes del Periodismo en Puebla. Puebla: AMPEP.

\section{Laura Flores Gómez}

Estudiante del noveno cuatrimestre de la Licenciatura en Comunicación de la Facultad de Ciencias de la Comunicación de la Benemérita Universidad Autónoma de Puebla. Actualmente labora en el Departamento de Comunicación Social y Relaciones Públicas del Sistema Estatal de Desarrollo Integral de la Familia (DIF) Puebla, en donde es fotógrafa, reportera, conductora y productora radiofónica.

\section{Angélica Mendieta Ramírez}

Doctora por el Instituto de Ciencias Sociales y Humanidades (ICSyH) de la Benemérita Universidad Autónoma de Puebla (BUAP-México). Maestría en Ciencias Políticas en la Facultad de Derecho de la BUAP, es Abogada, Notaria y Actuaria, realizó un Experto en Comunicación Interna y Externa en las Organizaciones (España), en verano de 2004 realizó una estancia en la Universidad de Harvard (EE.UU.). Fundadora y facilitadora del Modelo Universitario Minerva (MUM). Es Profesora-Investigadora de Tiempo Completo de la Facultad de Ciencias de la Comunicación de la BUAP, Miembro del Cuerpo Académico de "Comunicación Política". 